\title{
Experimental and kinetic modeling study on sooting tendencies of alkylbenzene isomers
}

Xiaogang Cheng a , Zhan Gao a, Fei Ren ${ }^{\text {a }}$, Stelios Rigopoulos ${ }^{\mathrm{b}}$, Lei Zhu ${ }^{\mathrm{a}, *}$, Zhen Huang ${ }^{\mathrm{a}}$

${ }^{a}$ Key Lab. for Power machinery and Engineering of M. O. E., Shanghai Jiao Tong University, Shanghai, China

${ }^{\mathrm{b}}$ Department of Mechanical Engineering, Imperial College London, Exhibition Road, London SW7 $2 A Z$, UK

\section{Corresponding authors: Lei Zhu}

Mailing address: School of Mechanical Engineering, Shanghai Jiao Tong University, Shanghai, P.R. China.

E-mail: tonyzhulei@gmail.com; tonyzhulei@sjtu.edu.cn (Lei Zhu*)

\begin{abstract}
Alkylbenzenes are major aromatic constituents of real transportation fuels and important surrogate components. In this study, 4 kinds of $\mathrm{C}_{8} \mathrm{H}_{10}$ and 8 kinds of $\mathrm{C}_{9} \mathrm{H}_{12}$ alkylbenzenes were tested in a laminar diffusion flame to investigate the influence of chemical structure on sooting tendency. The laser induced incandescence (LII) technique was applied to obtain the 2D distribution of soot volume fraction for calculating the yield sooting index (YSI) of test fuels. The processes of fuel oxidation and soot formation were simulated by a detailed chemical kinetic mechanism. The mechanism includes all $\mathrm{C}_{8} \mathrm{H}_{10}$ and $\mathrm{C}_{9} \mathrm{H}_{12}$ alkylbenzenes and includes species ranging from reactant to carbon particle. The simulation results of defined YSI were in good agreement with the experimental values. A database of sooting tendencies was established by experimental data, which shows that the number of substituents is positively correlated with the sooting tendency and that the sooting tendency of meta-substituent species is higher than other isomers. Through the analysis of reaction pathway and sensitivity, it was found that the main production pathway of A4 (pyrene) is via alkylbenzenes combination reactions at the early stage of combustion. The experimental database presented in this study is systematic and comprehensive for $\mathrm{C}_{8} \mathrm{H}_{10}$ and $\mathrm{C}_{9} \mathrm{H}_{12}$ alkylbenzenes, and is thus expected to be useful for soot model development and validation.
\end{abstract}

Keywords: Sooting tendency; LII; Alkylbenzene; Positional isomer; Soot model 


\section{Introduction}

The particulate emissions from combustion of transport fuels cause serious environmental pollution and severely threaten human health. Commercial transport fuels have a considerable part of aromatic hydrocarbons, jet fuel and diesel contain roughly $20 \%$ of alkylbenzenes ${ }^{[1]-[4]}$. The study of sooting characteristics of alkylbenzenes is important because PAHs (polycyclic aromatic hydrocarbon) are important precursors in the process of soot formation, as well as because they are important components in traditional transport fuels.

The sensitivities in sooting tendencies of real fuels or pure alkylbenzenes have been studied by different research groups: Das et al. ${ }^{[2]}$ reported experimental sooting tendencies of several diesel, jet fuels, surrogates, and pure compounds that are components of these surrogates (such as xylene and trimethylbenzene). They demonstrated two approaches to predict the sooting tendency of a fuel surrogate using experimental data. McEnally et al. ${ }^{[5]}$ measured gasolines and their surrogates containing enhanced alkylbenzenes. Their kinetic mechanism can reasonably predict the sooting tendencies for all the types of hydrocarbons found in gasolines and their mixtures. Liu et al. ${ }^{[6]}$ conducted a comparison study of the oxidation of n-propylbenzene, i-propylbenzene, 1,3,5 trimethylbenzene and 1,2,4 trimethylbenzene in a jet-stirred reactor. The production pathways of the aldehydes and PAHs in the oxidation were also discussed to understand soot formations. Benzyl and styrene were believed to be the main precursors of aldehydes and PAHs. Conturso et al. ${ }^{[7]}{ }^{[8]}$ studied the sooting tendency of four $\mathrm{C}_{8} \mathrm{H}_{10}$ isomers and three $\mathrm{C}_{9} \mathrm{H}_{12}$ isomers at atmospheric pressure, in a counter-flow diffusion ethylene flame. The experimental results showed that the effect of the alkyl chain on sooting tendency strongly depends on the combustion environment. The effect of molecular structures of alkylbenzenes on ignition characteristics of binary n-heptane blends was researched by Kang et al. ${ }^{[9]}$, their study include nine alkylbenzenes but their mechanism cannot analysis soot formation. Former researchers have thoroughly explored sooting mechanism of each alkylbenzene, including experiment and chemical mechanism. But few people experimented on all C8 and C9 alkylbenzenes systematically and focused on the influence of chemical structure. 
In this study, all different isomers of C8 and C9 alkylbenzenes were investigated systematically and comprehensively to reveal the influence of functional group structure on soot formation characteristics. Firstly, all $\mathrm{C}_{8} \mathrm{H}_{10}$ and $\mathrm{C}_{9} \mathrm{H}_{12}$ alkylbenzenes were measured by the LII method in a laminar diffusion methane flame to obtain yield sooting indices. Secondly, a combined chemical mechanism that includes all $\mathrm{C}_{8} \mathrm{H}_{10}$ and $\mathrm{C}_{9} \mathrm{H}_{12}$ alkylbenzenes was established to explain the experimental results, which includes species ranging from reactant to carbon particle. Finally, a systematically database of the sooting character of C 8 and $\mathrm{C} 9$ alkylbenzenes was established by experiment, which can be helpful for development and validation of soot formation mechanisms involving alkylbenzenes. Through analysis of the database, it is observed that the main formation pathway of A4 is combination reactions of alkylbenzenes at the early stage of combustion, and that the sooting tendency is correlated with substituent number and position.

\section{Experimental setup}

\subsection{Test fuels}

As mentioned above, the test fuels of this study are 4 kinds of $\mathrm{C}_{8} \mathrm{H}_{10}$ alkylbenzenes and 8 kinds of $\mathrm{C}_{9} \mathrm{H}_{12}$ alkylbenzenes shown in Table 1. The following uppercase words constitute the name of the fuel in the mechanism, followed by the common name of the fuel in parentheses. Experiments with 1,2,3 trimethylbenzene, 1,2 ethyl toluene, 1,3 ethyl toluene and 1,4 ethyl toluene have rarely been carried out in the literature.

Table 1. List of test fuels.

\begin{tabular}{lll}
\hline $\mathbf{C}_{\mathbf{8}} \mathbf{H}_{\mathbf{1 0}}$ alkylbenzenes & \multicolumn{2}{c}{$\mathbf{C}_{\mathbf{9}} \mathbf{H}_{\mathbf{1 2}}$ alkylbenzenes } \\
\hline $\mathrm{A} 1 \mathrm{C}_{2} \mathrm{H}_{5}($ ethyl benzene) & $\mathrm{A}_{1 \mathrm{C}_{3} \mathrm{H}_{7}(\mathrm{n} \text {-propyl benzene })}$ & $\mathrm{A} 1 \mathrm{CH}\left(\mathrm{CH}_{3}\right)_{2}$ (i-propyl benzene $)$ \\
OXYLENE(o-xylene) & $\mathrm{T} 124 \mathrm{MB}(1,2,4$ trimethylbenzene $)$ & $\mathrm{E} 12 \mathrm{~T}(1,2$ ethyl toluene $)$ \\
MXYLENE(m-xylene) & $\mathrm{T} 135 \mathrm{MB}(1,3,5$ trimethylbenzene $)$ & $\mathrm{E} 13 \mathrm{~T}(1,3$ ethyl toluene $)$ \\
PXYLENE(p-xylene) & $\mathrm{T} 123 \mathrm{MB}(1,2,3$ trimethylbenzene $)$ & E14T $(1,4$ ethyl toluene $)$ \\
\hline
\end{tabular}

Methane $\left(\mathrm{CH}_{4}\right)$ is selected as the base fuel $(0.24 \mathrm{~L} / \mathrm{min})$ according to Das et al. ${ }^{[10]}$. Via a series of preliminary experiments, the influence of mass fraction ratio ( $m_{\text {test fuel }} / m_{\text {mixed fuel }}$ ranging from $0.5 \%$ to $\left.1.75 \%\right)$ on $2 \mathrm{D}$ LII images was tested, and it was decided to experiment with a constant mass fraction ratio $1.5 \%(0.002387 \mathrm{~g} / \mathrm{min})$, under which the flame structure was stable and the LII data was distinguishable. 


\subsection{LII system}

The LII experiment system in this research has been described in a previous work ${ }^{[11][12]}$, the schematic of which is shown in Fig. 1. The coflow diffusion burner ${ }^{[13]}$ consists of two concentric brass tubes: a central fuel tube (I.D. $=$ $10.5 \mathrm{~mm}$ ) and an outer air tube (I.D. $=96.8 \mathrm{~mm}$ ), with the air (about $150 \mathrm{~L} / \mathrm{min}$ ) functioning both as oxidizing gas and as a shield for the flame to avoid interferences of environmental air.



Fig. 1. Schematic of the experimental setup.

A newly designed vaporizing system was designed for liquid fuels with higher viscosity and density. A short tee and a micro sample injector were prepared for fuel vaporizing. The tip of the injector is arranged on the central axis of the fuel tube to ensure that a trace amount of liquid fuel can be carried away completely by a large amount of base gas fuel. Both the fuel transportation tube and the burner are surrounded by a heater that can be heated to $473 \mathrm{~K}$ and $773 \mathrm{~K}$ respectively. The temperature is above the boiling point of the liquid fuel in this study, to avoid condensation of the test fuels during the transportation process.

\subsection{Data process}

The experimental results for soot were shown by a 2D LII figure with color bar, but this result is difficult to analyze quantitatively. The sooting tendency of diffusion flames has traditionally been characterized by apparatusindependent parameters such as the threshold soot index $(\mathrm{TSI}){ }^{[14]}$ or oxygen-extended sooting index (OESI) ${ }^{[15]}$. Since the focus of this study is on the effect of different fuels, the temperature, velocity, pressure and other similar 
experimental parameters are not relevant. The method of Das et al. ${ }^{[10]}$ is used to reduce the influence of irrelevant variables. In this method, a small amount of the test compound is added to a lightly sooting base flame, the amount of test fuel being too small to affect the soot concentration via indirect mechanisms such as dilution of the base fuel or changes in the flame temperature. Therefore, the measured sooting tendencies depend strongly on the direct chemical effects of the structure of the test component. Finally, we choose a normalized apparatus-independent parameter YSI developed by McEnally et al. ${ }^{[16]}$ to characterize the sooting tendency in this experiment. The maximum soot volume fractions $\left(f_{v, \text { max }, i}\right)$ can be converted into YSI by the following equation, where $\mathrm{A}$ and $\mathrm{B}$ are apparatus-specific parameters chosen such that the YSI of $n$-heptane $=10$, and the YSI of tetralin=100:

$\mathrm{YSI}_{i}=\left(\mathrm{YSI}_{A}-\mathrm{YSI}_{B}\right) \times \frac{f_{v, \max , i}-f_{v, \max , B}}{f_{v, \text { max }, A}-f_{v, \text { max }, B}}+\mathrm{YSI}_{B}$

The maximum soot volume fraction $\left(f_{v, \max }\right)$ is a necessary parameter to calculate the YSI. However, it is not correct to take the maximum value as $f_{v, \max }$, because the photocurrent signal of the ICCD camera may be influenced by external conditions and lead to a mistaking signal with extreme high or extreme low values of some pixels. Therefore, according to the method of Das ${ }^{[10]}$, the "peak-region $f_{v, \max }$ "was defined in this study to obtain a more representative and repeatable result.
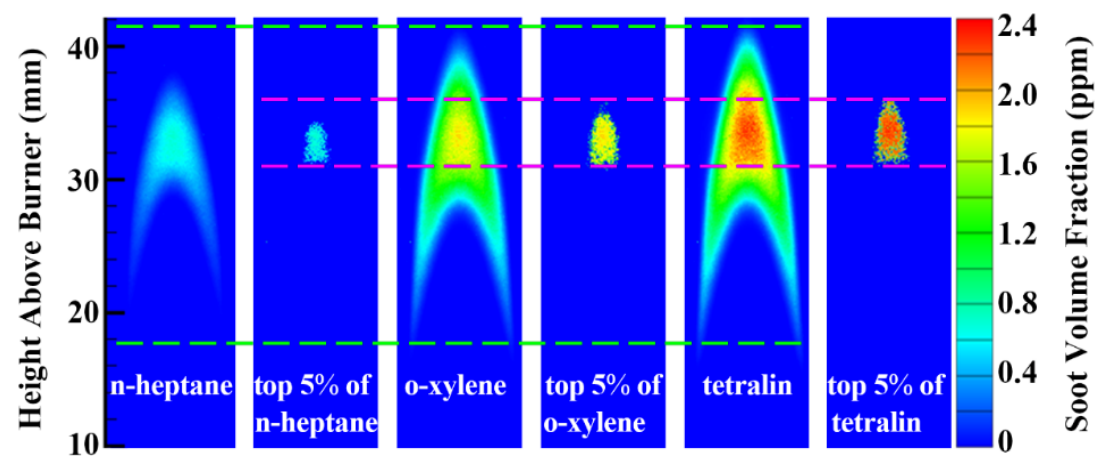

Fig. 2. Schematic after extracting peak-region.

In addition, since the soot volume fraction is directly proportional to the LII signal, Soot volume fraction can be obtained by multiplying the LII signal intensity by the conversion coefficient ${ }^{[1][17]}$. The pixels with the largest soot volume fraction of the first $5 \%$ are selected as the "peak-region $f_{v, \max }$ to calculate the YSI. This data process method 
has three advantages ${ }^{[10]}$ :

a. The fluctuation of the value $\left(f_{v, \max }\right)$ in the central region is smaller than in other regions.

b. The location and size of the peak-region are basically unchanged under different fuels and mixing ratios (Fig.

2).

c. The average value of $f_{v, \text { max }}$ in the "peak-region" is linearly correlated with the mixing ratio.

In order to obtain a more stable average value, $100 \mathrm{LII}$ images were collected for each fuel after the flame was stabilized. A program written in MATLAB was used to define the peak region of each image and extract the values. Finally, averaging and normalization calculations were performed.

\section{Chemical kinetic modeling}

\subsection{Fuel oxidation mechanism and soot mechanism}

The fuel oxidation mechanism used in this study is based on Liu et al. ${ }^{[6]}$. The mechanism was established by combining several widely validated mechanisms ${ }^{[18][21]}$ and expanded by analogy on some species such as ethyl toluene, hence it includes almost all kind of alkylbenzene species beside T123MB. 
Most soot mechanisms can only simulate up to A4 (pyrene), so a mechanism that can simulate soot is chosen in this study from the CRECK Modeling Group [22]. There are 20 classes of pseudo-species in the mechanism (named BIN1 to BIN20) to represent carbon particles from $0.81 \mathrm{~nm}$ to $193.32 \mathrm{~nm}$ in collision diameter. In this soot mechanism, the BIN series are divided into 3 parts: (1) BIN1 to BIN4 are heavy PAHs, which are considered in the gas-phase model particles; (2) BIN5 to BIN12 are primary particles with spherical shape; (3) BIN13 to BIN20 are assumed to be monodisperse aggregates or mass fractals containing a huge number of primary particles. If species between BIN13 to BIN20 are selected as the tested product for analysis, the process from fuel to soot can be completely included. Since the mole fraction of the BIN species in the next class is only about one hundredth of that in the previous class, the mole fraction of BIN after the 13th class is too small to analyze. Finally, BIN13A was selected as the tested product in this study for comparison with the experimental results.

\subsection{Mechanism combination and model setup}

The combined mechanism in this work was established by combining soot mechanisms and fuel oxidation mechanisms, the former serving as main mechanism and the latter as the sub mechanism. In addition, the parameters of T124MB and T135MB were referenced by analogy to complete the reaction of T123MB. The simulation results of T123MB in this paper were used only for reference, since the reaction coefficients were not verified. The complete reaction mechanism including 667 species and 18932 reactions, as well as the thermochemical data, were taken from the same reference. The mechanism file, thermochemical data file and validation analysis (Fig. S1) are available in the supplemental material.

\subsection{Numerical analysis tool}

Numerical simulations through the closed homogeneous reactor model (SENKIN) of Reaction Design's CHEMKIN PRO were performed with same thermodynamic parameters $(1500 \mathrm{~K}, 1 \mathrm{~atm})$, which resembles one node in whole coflow diffusion flame. The method is refer to Kholghy et al. ${ }^{[23]}$, because every node of the whole flame can be considered as a homogeneous reactor. Different equivalent ratio, temperature and other operating points has 
been tested in pre-simulation; whose parameters are determined in the end. The purpose of this paper is to explore the main reaction pathway of soot precursors for alkylbenzenes with different substituents. In addition, if the physical properties of each pseudo species (BINs) are assumed to be uniform, then the soot mole fraction is linearly related to the soot volume fraction, hence the mole fraction simulated by CHEMKIN can be directly used for qualitative analysis.

\section{Results and discussion}

\subsection{D-LII Signal}

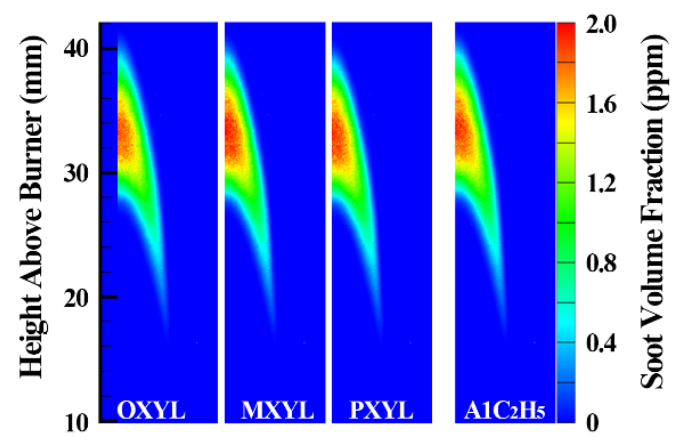

Fig. 3. Soot volume fraction distribution of C8 alkylbenzenes.



Fig. 4. Soot volume fraction distribution of C9 alkylbenzenes.

Figures 3 and 4 reflect the distribution in a diffusion flame of C8 and C9 alkylbenzenes. It can be seen from the two figures that the flame height and flame position hardly change among the 12 test fuels, and the distribution of soot follows the rule of thick middle with thin wings. Contour plots (Fig. 3) show that C8 alkylbenzenes are almost identical in soot volume fraction intensity and distribution; while which for C9 alkylbenzenes are distinguishable (Fig. 4). The soot volume fraction range of all the peak regions is from $2.0 \mathrm{ppm}$ to $2.4 \mathrm{ppm}$. 


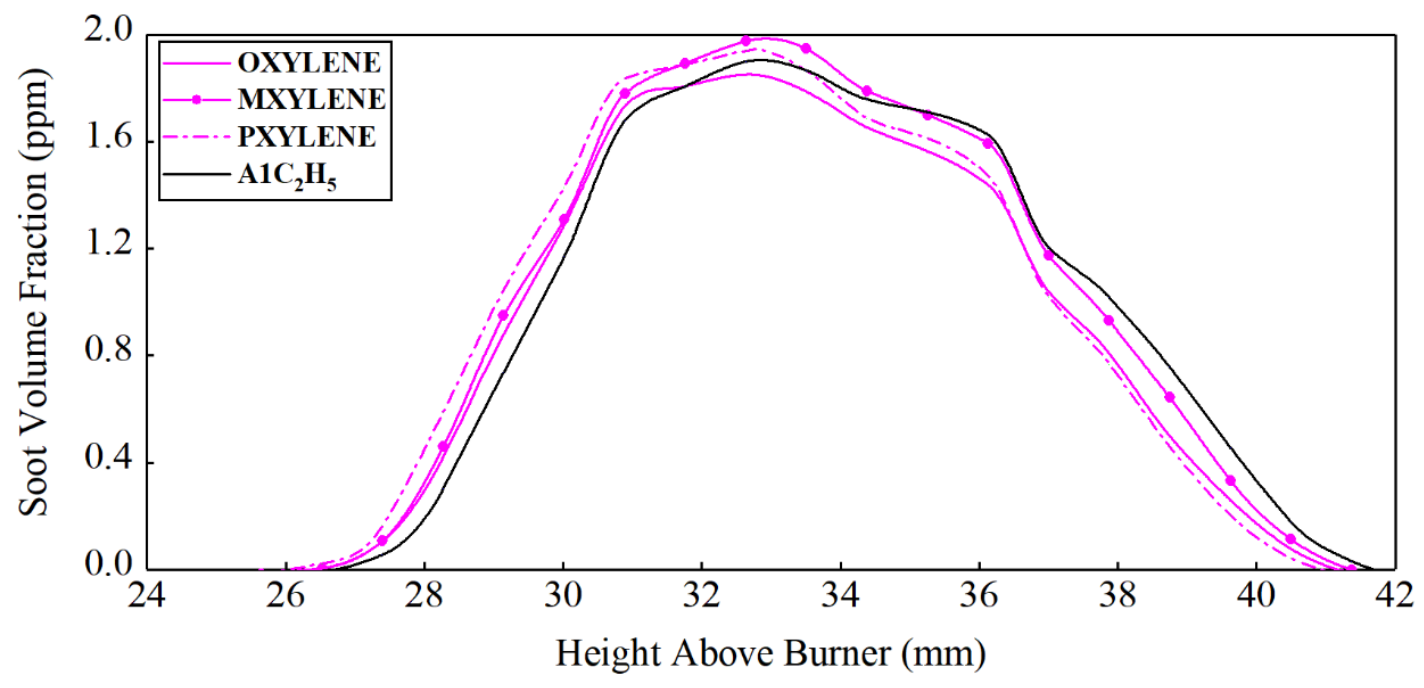

Fig. 5. Soot distribution of $\mathrm{C} 8$ alkylbenzenes along center line.

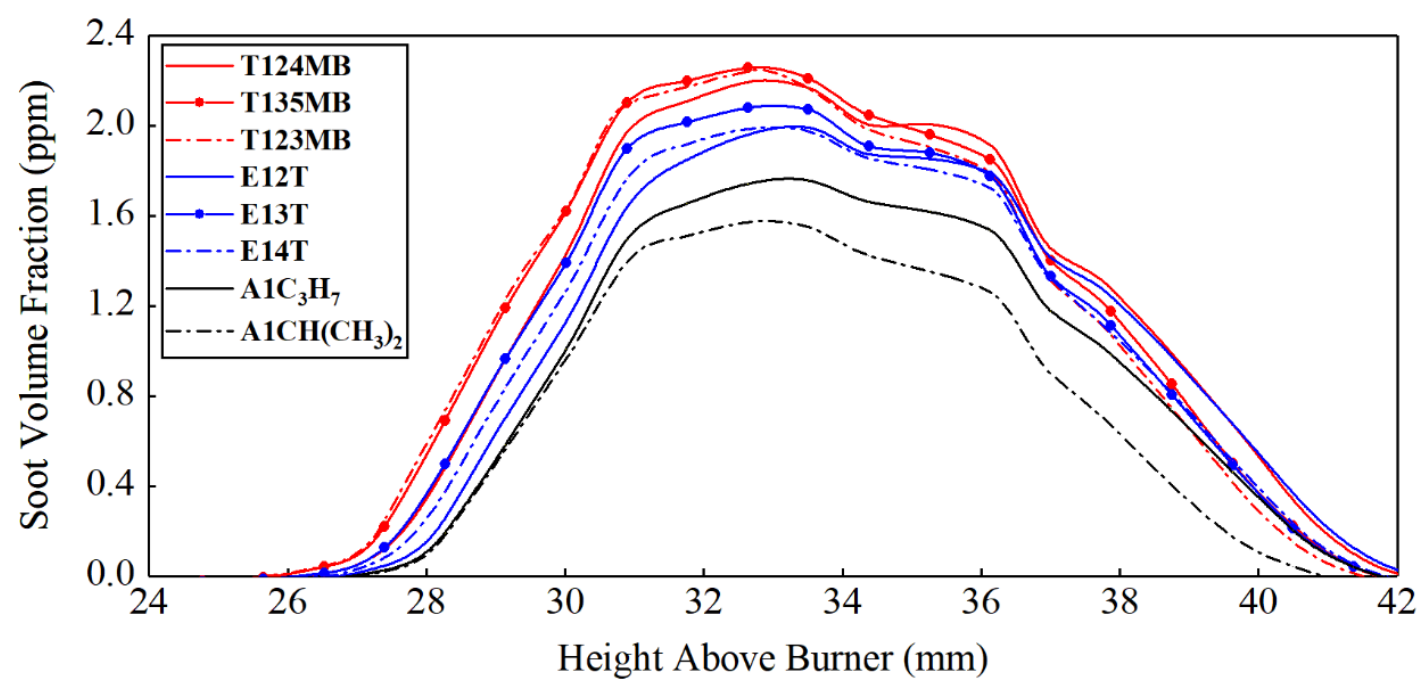

Fig. 6. Soot distribution of $\mathrm{C} 9$ alkylbenzenes along center line.

Figure 5 and 6 are drawn to reflect changes of soot volume fraction along the flame centerline by processing the data from 50 continuous LII images, the omitted error bars can be found in the supplemental material (Fig. S2-Fig. S13). As can be seen from Fig. 5 and Fig. 6, curves of alkylbenzenes with the same groups almost coincide, while those with different groups are distinguishable. This means that group position has less influence than group type. The order of sooting tendency can be summarized as follows: trimethylbenzene $>$ ethyl toluene, xylene, ethylbenzene > n-propyl benzene > i-propyl benzene. In terms of the shape of the curves, all curves are similar to normal distribution. At the position of 34-36 mm in the two figures, however, the curves have a ladder-shaped drop, caused by high temperature at the flame center that accelerates the oxidation reaction of newly formed carbon particles. In addition, 
it can be observed that curves with circle symbols are obviously higher than others in their own series, a fact that may reflect the dominant role of meta-substituents in the process of soot formation.

\subsection{Comparison of BIN13A}

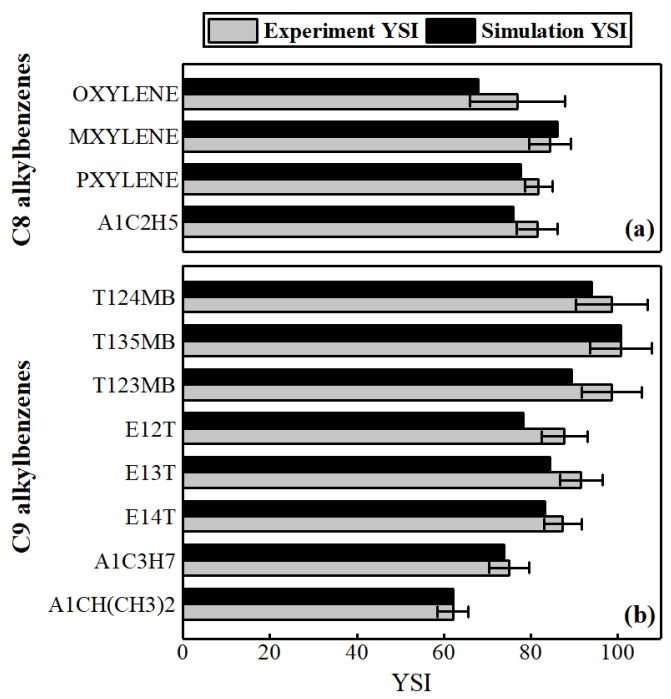

Fig. 7. Comparison of experimental and simulation results.

The mole fraction of BIN13A is converted into a dimensionless parameter, named as simulation YSI, through a normalizing process. In order to observe the trend of results more easily, the normalized upper point and lower point are set to the same as the experiment YSI (experiment YSI $_{\mathrm{i} \text {-propylbenzene }}=62.06$; experiment $\mathrm{YSI}_{1,3,5}$ trimethylbenzene $=100.72)$.

In Fig.7, the black bar represents the YSI of the simulation and the white one with error bar represents the YSI of the experiment. The result can be compared in $\mathrm{C} 8$ series or $\mathrm{C} 9$ series respectively, or between $\mathrm{C} 8$ series and $\mathrm{C} 9$ series. Since the experiment is designed under the condition of constant mass fraction, the carbon number is same in the former comparison method, so the influence of carbon number can be ignored. In the case of the latter comparison method, the difference in molar mass between the two series is so small that the effect of carbon number is overshadowed by the effect of chemical reactions.

In Fig. 7(a), the YSI of MXYLENE is the highest, whereas OXYLENE is the lowest, and PXYLENE and A1C2H5 are close to each other. Focus on Fig. 7(b), The YSI values are decreasing in the following order: 
trisubstituted series $>$ disubstituted series $>$ monosubstituted series. In the trisubstituted and disubstituted series, T135MB and E13T with meta-substituents have the highest YSI values in their series respectively. Upon analyzing the whole figure, the sooting tendency observed followed the order: trisubstituted series $>$ disubstituted series $>$ monosubstituted series; in addition, fuels with meta-substituents in their molecular structure have a higher sooting tendency. The underlying principle and reaction pathway will be described in detail in the following text.

\subsection{Reaction pathway: $C 8-A 4$}

The traditional pathway to form PAHs is ${ }^{[24]}$ : a pool with small molecule hydrocarbon radicals is produced by fuel pyrolysis; then the first ring (A1) is formed mainly by $\mathrm{C}_{2} \mathrm{H}_{2}+\mathrm{C}_{4} \mathrm{H}_{\mathrm{X}}$ and $\mathrm{C}_{3} \mathrm{H}_{3}$ recombination reaction; and finally A1 grows with $\mathrm{C}_{2} \mathrm{H}_{2}$ through the HACA mechanism.

Most hydrocarbons without benzene rings do follow the traditional PAHs formation process, but the analysis of simulation data shows that the combination mechanism used in this study has a completely different series of reaction pathways for hydrocarbons with benzene ring. These pathways allow alkylbenzenes to combine with each other and generate A4 directly, i.e. without the HACA pathway. In order to distinguish the traditional PAHs formation pathway and the combination reaction from alkylbenzenes to A4, the latter is called "CROA (Combination Reaction of Alkylbenzenes)-PATHWAY" in this paper. Here are 3 typical reactions for example ("R" represents for radical):

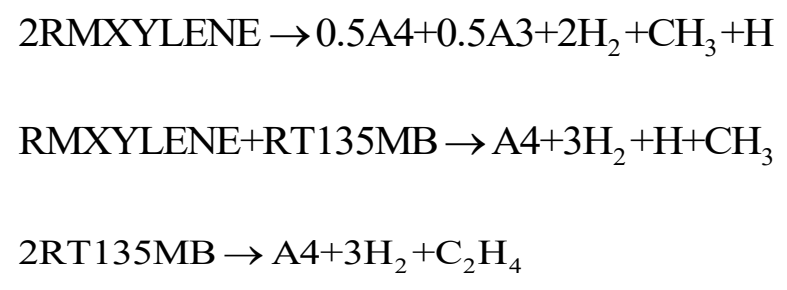




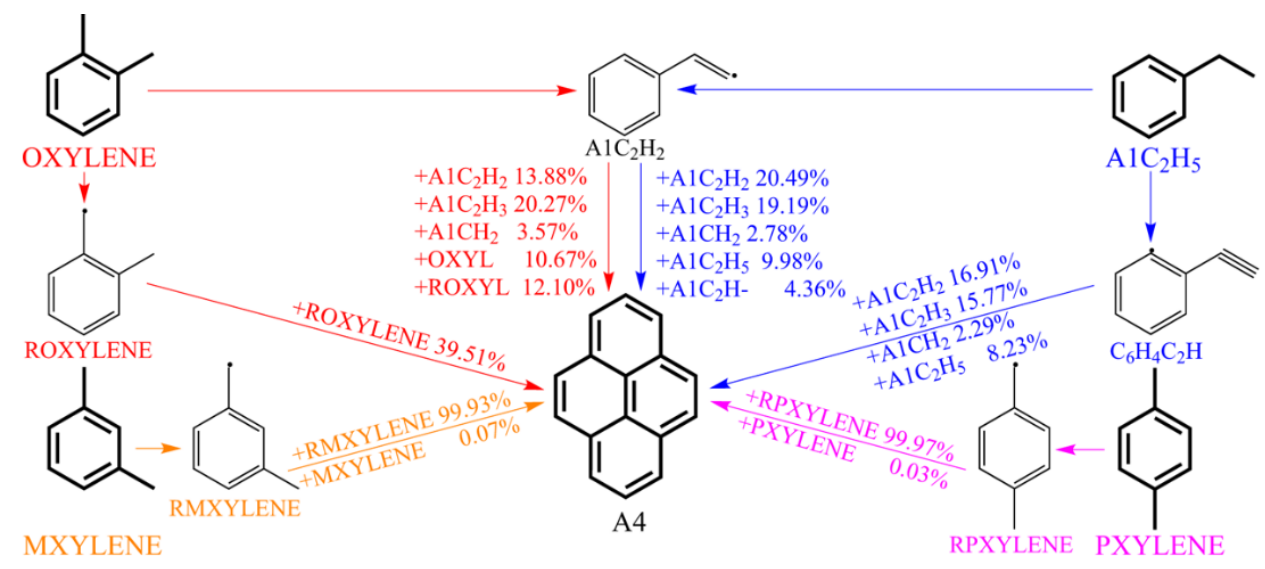

Fig. 8. Reaction pathways for A4 formation from 4 kinds of $\mathrm{C} 8$ alkylbenzenes $(1500 \mathrm{~K}, 1 \mathrm{~atm}$, fuel consumption rate $=80 \%, 4$ colors are used to distinguish pathways of 4 fuels).

Figure 8 is the reaction pathway from C8 alkylbenzenes to A4. The processes from four C8 alkylbenzene isomers to intermediates are drawn to describe the source of those intermediates. The processes from intermediates to A4 are illustrated with species and contribution percentage to A4.

Because of the different reaction rates of test fuels, it is difficult to determine a constant reaction time to analyze for all samples, and then fuel consumption rate of $80 \%$ is decided as the reference point to analyze the reaction pathway considering all test fuels. Although the rate of A4 formation by HACA mechanism is extremely high during the late combustion stage, the mole fraction of A4 is very low, because much of A4 is consumed by many oxidation reactions before it is converted to subsequent species (BIN series) under high temperature. When the fuel consumption rate is $80 \%$, on the one hand, the initial decomposition reaction of the fuel has been completed and sufficient reactants have been generated for CROA-PATHWAY; on the other hand, since the temperature of the whole system has not risen, A4 will not be consumed immediately. A4 produced at this time will have an obvious impact on the yield of subsequent species (BIN series), so $80 \%$ fuel consumption rate is selected as the reference point to analyze the reaction pathway.

As can be seen from Fig. 8, for the three kinds of xylenes, the radicals produced by the abstraction of a hydrogen atom from the methyl group are important intermediates for the formation reaction of A4. RXYLENE can polymerize 
either with itself or with XYLENE, but the self-reaction of RXYLENE plays a dominant role in the formation process of A4 (ROXYLENE 39.51\%; RMXYLENE 99.93\%; RPXYLENE 99.97\%). For $\mathrm{A}_{1} \mathrm{C}_{2} \mathrm{H}_{5}$, its intermediate products

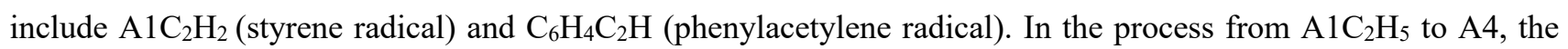
self-reaction of $\mathrm{A}_{1} \mathrm{C}_{2} \mathrm{H}_{2}$ accounts for the highest contribution rate $20.49 \%$, while the rate of reaction of $\mathrm{AlC}_{2} \mathrm{H}_{2}$ with $\mathrm{A}_{1} \mathrm{C}_{2} \mathrm{H}_{3}, \mathrm{~A}_{1} \mathrm{C}_{2} \mathrm{H}_{5}$ and other species is lower. The rates of production of the above reactions can be found in the supplemental material.

\subsection{Reaction pathway:C9-A4}

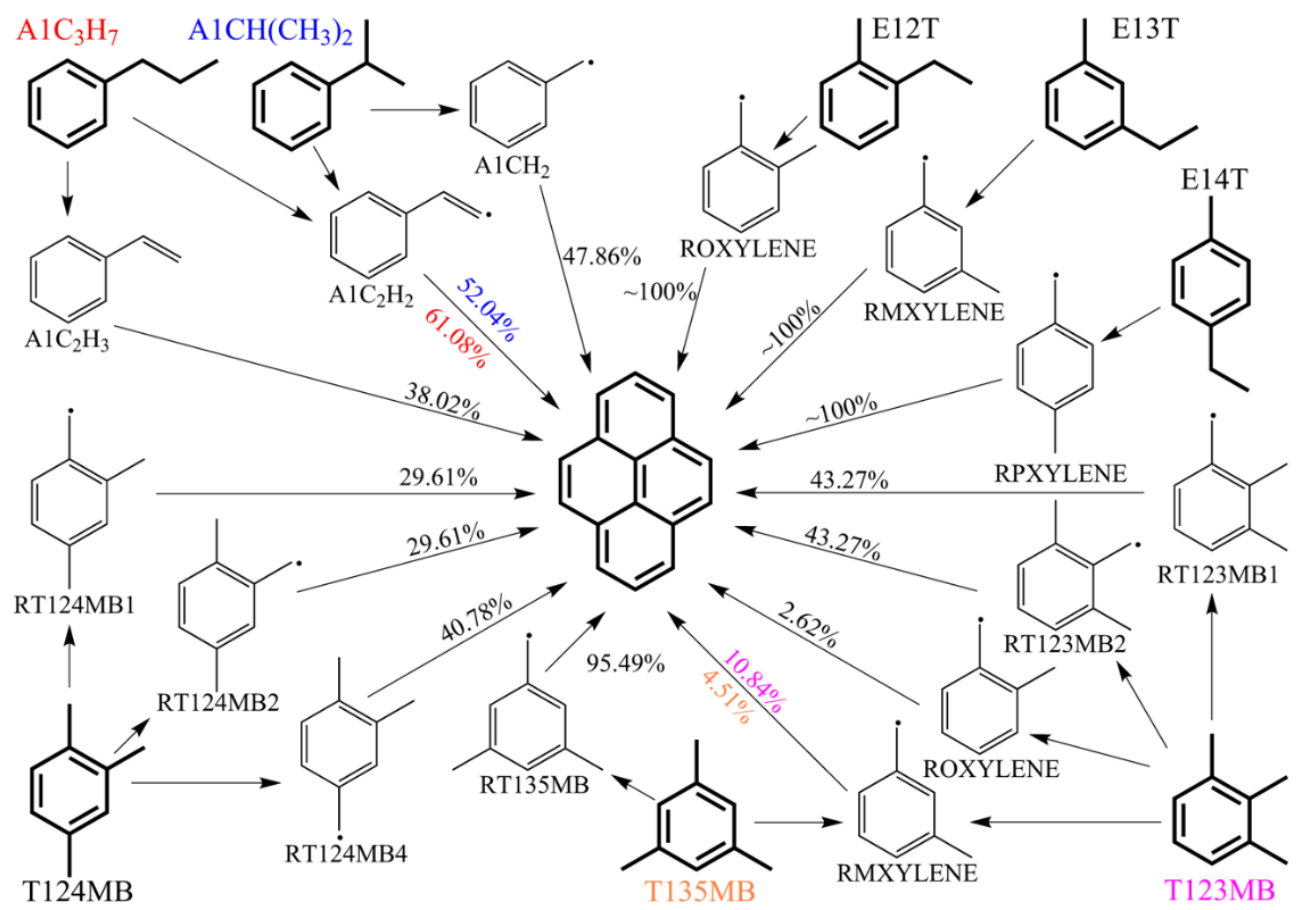

Fig. 9. Reaction pathways for A4 formation from 8 kinds of C9 alkylbenzenes (1500 K, 1 atm, fuel consumption rate $=80 \%, 4$ colors are only used to distinguish overlapping pathways of 4 fuels).

Figure 9 is the reaction pathway from C9 alkylbenzenes to A4. Since there are many combinations of dehydrogenation or demethylation of $\mathrm{C} 9$ alkylbenzenes, there are too many radicals to mark them all on the figure. Therefore, only several contribution rates of important species are shown in Fig. 9. As can be seen from Fig. 9, the PAHs formation pathways of three kinds of ethyl toluenes (E12T, E13T and E14T) are simple, and A4 is basically generated by RXYLENE with the same substituent position through self-reaction. The pathways of three 
trimethylbenzenes (T124MB, T135MB, T123MB) are more complex, because of the primary pathways are through a series of reactions of trimethylbenzene radicals (e.g. RT124MB1). The pathways of $\mathrm{AlC}_{3} \mathrm{H}_{7}$ and $\mathrm{A} 1 \mathrm{CH}\left(\mathrm{CH}_{3}\right)_{2}$ are very similar to that of $\mathrm{A}_{1} \mathrm{C}_{2} \mathrm{H}_{5}$ (ethylbenzene) in Fig. 8, the reactions pass through important intermediates such as

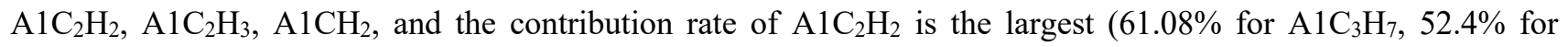
$\left.\mathrm{A} 1 \mathrm{CH}\left(\mathrm{CH}_{3}\right)_{2}\right)$ as ethylbenzene $(56.8 \%)$.

Based on the comprehensive analysis of C9-A4 and C8-A4, it could be concluded that the rate of CROAPATHWAY reaction was much higher than that of the HACA mechanism in the early stages of the reaction. An analysis regarding the number of substituent shows that the trisubstituted radicals have a higher tendency to generate A4 than the disubstituted radicals (e.g. RT135MB 95.49\%>RMXYLENE 4.51\% in the reaction from T135MB to A4) and the disubstituted radicals have a higher tendency to generate A4 than the monosubstituted radicals (e.g. ROXYLENE $39.51 \%>\mathrm{A} 1 C_{2} \mathrm{H}_{2} 13.88 \%$ in the reaction from OXYLENE to A4). An analysis regarding the type of substituent shows that the meta-substituted radical was higher than other disubstituted radicals (e.g. RMXYLENE 10.84\% $>$ ROXYLENE $2.62 \%$ in the reaction from T123MB to A4) and the radical with (E)-Ethenediide was higher than other monosubstituted radicals (e.g. $\mathrm{A}_{1} \mathrm{C}_{2} \mathrm{H}_{2} 61.08 \%>\mathrm{AlC}_{2} \mathrm{H}_{3} 38.02 \%$ in the reaction from $\mathrm{A}_{1} \mathrm{C}_{3} \mathrm{H}_{7}$ to $\mathrm{A} 4$ ). 


\begin{tabular}{|c|c|c|}
\hline OXYLENE & R16486 ROXYLENE+ROXYLENE $=>0.5 \mathrm{~A} 4+0.5 \mathrm{~A} 3+2 \mathrm{H} 2+\mathrm{CH} 3+\mathrm{H}$ & \\
\hline MXYLENE & R16893 RMXYLENE+RMXYLENE $=>0.5 \mathrm{~A} 4+0.5 \mathrm{~A} 3+2 \mathrm{H} 2+\mathrm{CH} 3+\mathrm{H}$ & \\
\hline \multirow[b]{2}{*}{ PXYLENE } & R17489 RPXYLENE+RPXYLENE $=>0.5 \mathrm{~A} 4+0.5 \mathrm{~A} 3+2 \mathrm{H} 2+\mathrm{CH} 3+\mathrm{H}$ & \\
\hline & R17507 RPXYLENE+PXYLENE $=>0.5 \mathrm{~A} 4+0.5 \mathrm{~A} 3+3 \mathrm{H} 2+\mathrm{CH} 3$ & \\
\hline \multirow{3}{*}{$\mathrm{A}_{1} \mathrm{C}_{2} \mathrm{H}_{5}$} & $\mathrm{R} 01188 \mathrm{AlC} 2 \mathrm{H} 2+\mathrm{A} 1 \mathrm{C} 2 \mathrm{H} 5=>0.5 \mathrm{~A} 4+0.5 \mathrm{~A} 3+2 \mathrm{H} 2+\mathrm{CH} 3$ & \\
\hline & $\mathrm{R} 01187 \mathrm{AlC} 2 \mathrm{H} 2+\mathrm{AlC} 2 \mathrm{H} 3=>\mathrm{A} 4+2 \mathrm{H} 2+\mathrm{H}$ & \\
\hline & $\mathrm{R} 01106 \mathrm{~A} 1 \mathrm{C} 2 \mathrm{H} 2+\mathrm{A} 1 \mathrm{C} 2 \mathrm{H} 2=>\mathrm{A} 4+\mathrm{H} 2+2 \mathrm{H}$ & \\
\hline \multirow{3}{*}{ T124MB } & R18065 RT124MB4+RT124MB4 $=>\mathrm{A} 4+3 \mathrm{H} 2+\mathrm{C} 2 \mathrm{H} 4+2 \mathrm{H}$ & \\
\hline & R18225 RT124MB1+RT124MB1 $>>\mathrm{A} 4+3 \mathrm{H} 2+\mathrm{C} 2 \mathrm{H} 4+2 \mathrm{H}$ & \\
\hline & R18145 RT124MB2+RT124MB2 $=>\mathrm{A} 4+3 \mathrm{H} 2+\mathrm{C} 2 \mathrm{H} 4+2 \mathrm{H}$ & \\
\hline \multirow{4}{*}{ T135MB } & R18554 RT135MB+RT135MB $=>\mathrm{A} 4+3 \mathrm{H} 2+\mathrm{C} 2 \mathrm{H} 4+2 \mathrm{H}$ & \\
\hline & R16935 RMXYLENE+RT135MB $=>\mathrm{A} 4+3 \mathrm{H} 2+\mathrm{CH} 3+\mathrm{H}$ & \\
\hline & R18553 RT135MB+RT135MB $=>$ A4+3H2+2CH3 & \\
\hline & R16893 RMXYLENE+RMXYLENE $=>0.5 \mathrm{~A} 4+0.5 \mathrm{~A} 3+2 \mathrm{H} 2+\mathrm{CH} 3+\mathrm{H}$ & \\
\hline \multirow{5}{*}{ T123MB } & R18829 RT123MB1+RT123MB1 $\Rightarrow$ A44+3H2+C2H4+2H & \\
\hline & R18909 RT123MB2+RT123MB2 $=>$ A4+3H2+C2H4+2H & \\
\hline & R16936 RMXYLENE+RT123MB1=>A4+3H2+CH3+H & \\
\hline & R16937 RMXYLENE+RT123MB2=>A4+3H2+CH3+H & \\
\hline & R16526 ROXYLENE+RT123MB1 $=>\mathrm{A} 4+3 \mathrm{H} 2+\mathrm{CH} 3+\mathrm{H}$ & \\
\hline E12T & R16486 ROXYLENE+ROXYLENE $=>0.5 \mathrm{~A} 4+0.5 \mathrm{~A} 3+2 \mathrm{H} 2+\mathrm{CH} 3+\mathrm{H}$ & \\
\hline E13T & R16893 RMXYLENE+RMXYLENE $=>0.5 \mathrm{~A} 4+0.5 \mathrm{~A} 3+2 \mathrm{H} 2+\mathrm{CH} 3+\mathrm{H}$ & \\
\hline E14T & R17489 RPXYLENE+RPXYLENE $=>0.5 \mathrm{~A} 4+0.5 \mathrm{~A} 3+2 \mathrm{H} 2+\mathrm{CH} 3+\mathrm{H}$ & \\
\hline \multirow{2}{*}{$\mathrm{AlC}_{3} \mathrm{H}_{7}$} & $\mathrm{R} 01187 \mathrm{AlC} 2 \mathrm{H} 2+\mathrm{AlC} 2 \mathrm{H} 3=>\mathrm{A} 4+2 \mathrm{H} 2+\mathrm{H}$ & \\
\hline & $\mathrm{R} 01075 \mathrm{AlCH} 2+\mathrm{A} 1 \mathrm{C} 2 \mathrm{H} 2=>0.5 \mathrm{~A} 4+0.5 \mathrm{~A} 3+\mathrm{H} 2+2 \mathrm{H}$ & \\
\hline $\mathrm{A} 1 \mathrm{CH}\left(\mathrm{CH}_{3}\right)_{2}$ & $\mathrm{R} 01075 \mathrm{~A} 1 \mathrm{CH} 2+\mathrm{A} 1 \mathrm{C} 2 \mathrm{H} 2=>0.5 \mathrm{~A} 4+0.5 \mathrm{~A} 3+\mathrm{H} 2+2 \mathrm{H}$ & \\
\hline \multirow{2}{*}{ Test fuels } & \multirow{2}{*}{ CROA reactions } & $\begin{array}{lll}0.2 & 0.4 & 0.6\end{array}$ \\
\hline & & Sensitivity coefficients \\
\hline
\end{tabular}

Fig. 10. Sensitivity analysis of CROA-PATHWAY $(1500 \mathrm{~K}, 1 \mathrm{~atm}$, fuel consumption rate $=80 \%)$.

Figure 10 gives the sensitivity coefficients of CROA-PATHWAY in several test fuels, these reactions are extracted from the top 10 reactions with the highest sensitivity coefficients (including positive and negative coefficients), other reactions and their coefficients can be found in supplemental material. As can be seen in Fig. 10, CROA-PATHWAY indeed takes an important part in A4 formation, each fuel has at least one CROA reaction, and the total CROA sensitivity coefficient of each fuel is significant. In addition, many conclusions can be drawn from the comparative analysis between different fuels. Xylene, ethyl toluene and propyl benzene have only one or two CROA reactions with high sensitivity coefficients; however, ethyl benzene and trimethylbenzene have more than three CROA reactions, the sensitivity of each reaction is evenly distributed (The former fuels called one-CROA-fuels and the latter fuels called multiple-CROA-fuels). This indicates that for one-CROA-fuels, the A4 formation process is dominated by a single pathway, while multiple-CROA-fuels have more pathways. This conclusion is basically consistent with the reaction pathway in Figs. 8 and 9, except for OXYLENE, which only has one CROA reaction 
with 0.68 coefficient, not same as other one-CROA-fuels such as MXYLENE (sensitivity coefficient=0.97). Combined with Fig. 8, the special case can be explained that OXYLENE have many other CROA reactions to form A4, but these reactions are not sensitive enough to be shown in Fig. 10.

As mentioned above, substituent number and position are important to soot formation. In terms of substituent number, it is obviously that reactions include trisubstituted radicals are more sensitive than disubstituted radicals (R18554 > R16935 > R16893, in T135MB). It explains the fact that YSIs of trimethylbenzenes are bigger than xylene and ethyl toluene in another way. For substituent position, the reactions with different trimethylbenzene radicals have different sensitivity coefficient (R18065, R18225, R18145, R18554, R18829 and R18909), but the parameters (A, b and E) in mechanism are completely same. It means that the different coefficients are influenced by radical concentration dominantly, so the figure cannot reflect sensitivity of reactions with positional isomers.

\subsection{Process analysis of soot formation}

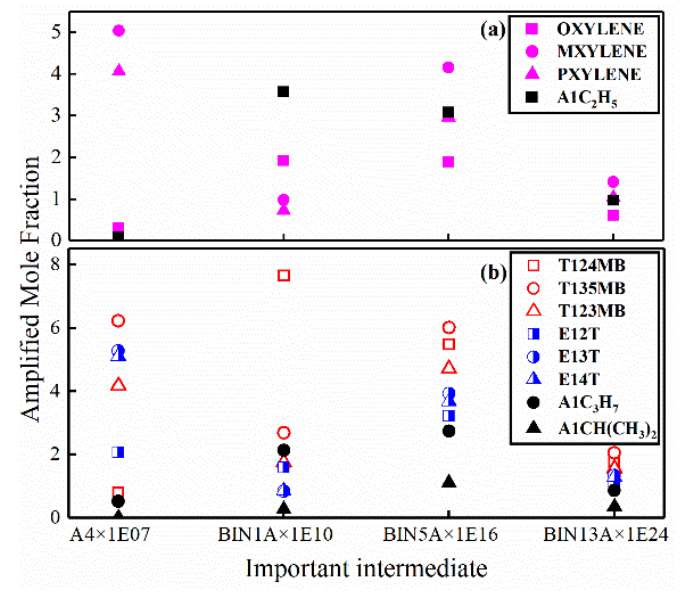

Fig. 11. Comparison of soot formation process.

The reaction pathway from A4 to BIN13A is difficult to draw, because the generation peaks of them are far apart in reaction time, so this paper chooses another way to express the material evolution on the time scale. Figure 11 is drawn to reflect the process of soot formation. The horizontal axis of the figure is A4, BIN1A, BIN5A and BIN13A, the vertical axis is the maximum mole fraction of the total reaction (which is amplified by coefficients). In soot mechanism of Saggese et al. ${ }^{[22]}$, BIN1-BIN4 represent heavy PAHs, BIN5-BIN12 represent primary particle, 
BIN13-BIN20 represent monodisperse aggregates. Soot formation can be divided into three steps: 1. Heavy PAHs formation; 2. Soot inception and surface growth; 3 . Soot coalescence and aggregation. In order to compare the reaction strength of different fuels in the same step, many complex reaction pathways have been omitted and reduced to curves across the time scale, the relative slope of the curves can indicate the relative strength of the reaction in the same step (A4-BIN1A for "Heavy PAHs formation", BIN1A-BIN5A for "Soot inception and surface growth", BIN5A-BIN13A for "Soot coalescence and aggregation"). It can be obtained that there is no fluctuation in the third step, but the first two steps are divided into two different forms. In first two steps, most fuels follow the trend of falling first and then rising (such as MXYLENE and T135MB), these fuels produced enough A4, but can not convert them to heavy PAHs efficiently, while their ability of soot inception and surface growth is considerable. Other fuels rising first and then falling (such as A1C2H5 and T124MB), these fuels can form heavy PAHs in a large quantity, but their reaction strength in the second step is far from the former fuels. In addition to these two kinds of fuels, $\mathrm{A} 1 \mathrm{CH}(\mathrm{CH} 3) 2$ is a special case with continuing upward trend in first two steps, but its curve is too flat to analyze. Thus, in comparison with most fuels, for A1C2H5, OXYLENE, A1C3H7, T124MB, the reaction to product heavy PAHs is more intense, but the soot inception reaction is relatively slow.

\section{Conclusions}

In the present study, the soot formation characteristics of $\mathrm{C}_{8} \mathrm{H}_{10}$ and $\mathrm{C}_{9} \mathrm{H}_{12}$ alkylbenzenes were measured experimentally and analyzed through simulation work. Experiments were conducted, where the soot volume fraction of laminar diffusion flames was measured by LII method, and then experiment YSI was obtained by averaging and normalization process. Furthermore, simulations were carried out with the combined mechanism in order to calculate the mole fraction of the pseudo-species (BIN13A), and then a similar data processing method was used to obtain the simulation YSI. By comparing the experiment and simulation results and analyzing of reaction pathways, the following conclusions can be drawn:

1. The sooting tendency is affected by the substituent number. The sooting tendency of trimethylbenzene is 
higher than ethyl toluene. In addition, the sooting tendency of ethyl toluene is higher than two kinds of propyl benzenes. It is speculated that the number of substituents is positively correlated with the sooting tendency.

2. The sooting tendency is also affected by the substituent position. Sooting tendency of MXYLENE, T135MB and E13T were all higher than their position isomers. It is speculated that the sooting tendency of meta-substituent species was higher than ortho-substituent and para-substituent.

3. Analysis of reaction pathway and sensitivity show that the main formation pathway of A4 is CROAPATHWAY, rather than HACA mechanism in early stage of combustion. In CROA-PATHWAY, species or radicals with benzene rings react with similar species with benzene rings to form A4 directly.

4. Process analysis shows that by comparison with most test fuels, for A1C2H5, OXYLENE, A1C3H7, T124MB, the reaction to product heavy PAHs is more intense, but the soot inception reaction is relatively slow.

In sum, this paper analyzes the substituents effect on soot formation for isomers and validates the dominate status of CROA-PATHWAY in pyrene formation process by both experiment and chemical kinetic simulation, which could provide valuable information for surrogate design and soot mechanism modification.

\section{Acknowledgments}

The authors would like to thank the National Science Foundation of China (Project No. 51436005; 91741120; 51676125) for support. 


\section{References}

[1] T.M. Lovestead, J.L. Burger, N. Schneider, T.J. Bruno, Comprehensive assessment of composition and thermochemical variability by high resolution GC/QToF-MS and the advanced distillation-curve method as a basis of comparison for reference fuel development, Energy Fuels 30 (2016) 10029-10044.

[2] D.D. Das, C.S. McEnally, T.A. Kwan, J.B. Zimmerman, W.J. Cannella, C.J. Mueller, L.D. Pfefferle, Sooting tendencies of diesel fuels, jet fuels, and their surrogates in diffusion flames. Fuel 197 (2017) 445-458.

[3] J.A. Cooke, M. Bellucci, M.D. Smooke, A. Gomez, A. Violi, T. Faravelli, E. Ranzi, Computational and experimental study of JP-8, a surrogate, and its components in counterflow diffusion flames. Proc. Combust. Inst. 30 (2005) 439-46.

[4] S. Dooley, S.H. Won, J. Heyne, T.I. Farouk, Y. Ju, F.L. Dryer, et al. The experimental evaluation of a methodology for surrogate fuel formulation to emulate gas phase combustion kinetic phenomena. Combust. Flame 159 (2012) 1444-66.

[5] C.S. McEnally, Y. Xuan, P.C. St. John, D.D. Das, A. Jain, S. Kim, T.A. Kwan, L.K. Tan, J. Zhu, L.D. Pfefferle, Sooting tendencies of co-optima test gasolines and their surrogates. Proc. Combust. Inst. 37 (2019) 961-968.

[6] Y.X. Liu, Z.Y. Tian, Oxidation chemistry of four $\mathrm{C}_{9} \mathrm{H}_{12}$ isomeric transportation fuels: Experimental and modeling studies. Combust. Flame 205 (2019) 165-179.

[7] M. Conturso, M. Sirignano, A. D'Anna, Effect of alkylated aromatics on particle formation in diffusion flames: An experimental study. Exp. Therm Fluid Sci. 73 (2016) 27-32.

[8] M. Conturso, M. Sirignano, A. D’Anna, Effect of C9H12 alkylbenzenes on particle formation in diffusion flames: An experimental study. Fuel 191 (2017) 204-211.

[9] D. Kang, D. Kim, K.H. Yoo, A. Violi, A. Boehman, The effect of molecular structures of alkylbenzenes on ignition characteristics of binary n-heptane blends. Proc. Combust. Inst. 37 (2019) 4681-9.

[10] D.D. Das, P.C. St. John, C.S. McEnally, S. Kim, L.D. Pfefferle, Measuring and predicting sooting tendencies of oxygenates, alkanes, alkenes, cycloalkanes, and aromatics on a unified scale. Combust. Flame 190 (2018) 349-364.

[11] Z. Gao, L. Zhu, X. Zou, C. Liu, B. Tian, Z. Huang, Soot reduction effects of dibutyl ether (DBE) addition to a biodiesel surrogate in laminar coflow diffusion flames. Proc. Combust. Inst. 37 (2019) 1265-1272.

[12] Z. Gao, X. Cheng, F. Ren, L. Zhu, Z. Huang, Compositional Effects on Sooting Tendencies of Diesel Surrogate Fuels with Four Components. Energy Fuels 34 (2020) 8796-8807.

[13] M. Si, Q. Cheng, J. Song, Y. Liu, M. Tao, C. Lou, Study on inversion of morphological parameters of soot aggregates in hydrocarbon flames. Combust. Flame 183 (2017) 261-70.

[14] H.F. Calcote, D.M. Manos, Effect of molecular structure on incipient soot formation. Combust. Flame 49 (1983) 289-304.

[15] E.J. Barrientos, M. Lapuerta, A.L. Boehman, Group additivity in soot formation for the example of C-5 oxygenated hydrocarbon fuels. Combust. Flame 160 (2013) 1484-1498.

[16] C. Mcenally, L. Pfefferle, Improved sooting tendency measurements for aromatic hydrocarbons and their implications for naphthalene formation pathways. Combust. Flame 148 (2007) 210-222.

[17] B. Tian, Y. Gao, S. Balusamy, S. Hochgreb, High spatial resolution laser cavity extinction and laser-induced incandescence in low-soot-producing flames. Appl. Phys. B 120 (2015) 469-487.

[18] Y.X. Liu, B.Y. Wang, J.J. Weng, A wide-range experimental and modeling study of oxidation and combustion of n-propylbenzene. Combust. Flame 191 (2018) 53-65.

[19] J.J. Weng, Y.X. Liu, B.Y. Wang, Experimental and kinetic investigation of 1,2,4-trimethylbenzene oxidation at low temperature. Proc. Combust. Inst. 36 (2017) 909-917.

[20] B.Y. Wang, D. Yu, G.F. Pan, Y.X. Liu, J.J. Weng, Z.Y. Tian, An experimental and modeling study on the low temperature oxidation of surrogate for JP-8 part I: Neat 1,3,5-trimethylbenzene. Proc. Combust. Inst. 10 (2018) $507-516$. 
[21] B.Y. Wang, New insights in the low-temperature oxidation of acetylene. Proc. Combust. Inst. 36 (2017) 355363.

[22] C. Saggese, S. Ferrario, J. Camacho, A. Cuoci, A. Frassoldati, E. Ranzi, H. Wang, T. Faravelli, Kinetic modeling of particle size distribution of soot in a premixed burner-stabilized stagnation ethylene flame. Combust. Flame 162 (2015) 3356-3369.

[23] M.R. Kholghy, J. Weingarten, M.J. Thomson, A study of the effects of the ester moiety on soot formation and species concentrations in a laminar coflow diffusion flame of a surrogate for B100 biodiesel. Proc. Combust. Inst. 35 (2015) 905-912.

[24] H. Wang, M. Frenklach, A detailed kinetic modeling study of aromatics formation in laminar premixed acetylene and ethylene flames. Combust. Flame 110 (1997)173-221. 